\title{
HUBUNGAN USIA MENARCHE DAN STATUS GIZI TERHADAP KEJADIAN DISMINORE PADA SISWI SMP KELAS 2 DI SMPN 57 KECAMATAN PINANG RAYA KABUPATEN BENGKULU UTARA
}

The Relationship between Age of Menarche and Nutritional Status with Disminore Events on Junior High School Grade 1 Students at SMPN 57, Pinang Raya District, North Bengkulu Regency

\author{
Yulita Elvira Silviani ${ }^{1}$, Ersa Pravitasari $\mathrm{MS}^{1}$, Buyung Keraman ${ }^{2}$ \\ ${ }^{1}$ Program Studi DIV Kebidanan STIKES Tri Mandiri Sakti Bengkulu \\ ${ }^{2}$ Program Studi Matematika FMIPA Universitas Bengkulu \\ Email:vivielvira92@gmail.com
}

\begin{abstract}
ABSTRAK
Sebagian wanita mendapatkan menstruasi tanpa keluhan, namun tidak sedikit dari mereka yang mendapatkan menstruasi disertai keluhan sehingga mengakibatkan rasa ketidaknyamanan berupa dismenore. Penelitian ini bertujuan untuk mengetahui hubungan usia menarche dan status gizi terhadap kejadian disminore pada siswi SMP kelas 2 di SMPN 57 Kecamatan Pinang Raya Kabupaten Bengkulu Utara. Penelitian ini telah dilaksanakan pada tanggal 16-30 Juli 2018 di SMPN 57 Kecamatan Pinang Raya Kabupaten Bengkulu Utara. Desain peneitian yang digunakan pada penelitian ini adalah Survey Analitik dengan pendekatan Cross Sectional. Pengambilan sampel dengan cara Total Sampling, total seluruh populasi 37 orang. Teknik pengambilan data adalah data primer dengan menggunakan kuesioner dan data sekunder. Teknik analisis data adalah data Analisis Univariat dan Analisis Bivariat. Hasil penelitian dari 37 responden, terdapat 123 orang $(62,2 \%)$ dengan usia menarche 11-14 tahun, 23 orang $(62,2 \%)$ dengan status gizi kurus, dan 16 orang $(43,2 \%)$ nyeri ringan saat menstruasi. Tidak ada hubungan usia menarche dengan kejadian dismonire pada Siswi SMP kelas 2 di SMPN 57 Kecamatan Pinang Raya Kabupaten Bengkulu Utara. Ada hubungan status gizi dengan kejadian disminore pada Siswi SMPN kelas 2 di SMPN 57 Kecamatan Pinang Raya Kabupaten Bengkulu Utara.
\end{abstract}

Kata Kunci: usia menarche, status gizi, disminore

\footnotetext{
ABSTRACT

Some women get menstruation without complaints, but not a few of them get menstruation accompanied by complaints resulting in a feeling of discomfort in the form of dysmenorrhea. This study aimed to determine the relationship of age of menarche and nutritional status to disminore events in junior high school students in grade 2 at SMPN 57 Pinang Raya subdistrict, Bengkulu Utara Regency. This research was conducted on 1630 July 2018 at SMPN 57 Pinang Raya District, Bengkulu Utara Regency.
} 
The research design used in this study was an Analytical Survey with a Cross Sectional approach. Sampling by Total Sampling, the total population of 37 people. Data collection techniques were primary data using questionnaires and secondary data. Data analysis techniques were Univariate Analysis and Bivariate Analysis data. The results of the study: of 37 respondents there was 23 people (62.2\%) with menarche age 11-14 years, 23 people (62.2\%) with underweight nutritional status, and 16 people (43.2\%) had mild pain during menstruation. There was no relationship between age of menarche with incidence of dismonire in High School Students in grade 2 at SMPN 57, Pinang Raya District, Bengkulu Utara Regency. There was a relationship between nutritional status with the incidence of disminore in High School Students in Grade 2 at SMPN 57, Pinang Raya District, Bengkulu Utara Regency

\section{Keywords: age of menarche, disminore, nutritional status}

\section{A. Pendahuluan}

Setiap wanita memiliki pengalaman menstruasi yang berbeda-beda. Berbagai masalah yang timbul pada menstruasi merupakan masalah ginekologi yang sering dikeluhkan oleh remaja, seperti ketidakaturan menstruasi, menoragia, dismenorea, dan gejala lain yang berhubungan. Setiap bulan wanita yang berusia 12-49 tahun tidak sedang hamil dan belum menikah mengalami masalah yang dialami banyak wanita yaitu rasa tidak nyaman atau rasa nyeri yang hebat menstruasi. Hal ini bisa disebut disminore.

Di Turki menemukan bahwa dismenorea merupakan gangguan menstruasi dengan prevalensi terbesar $(89,5 \%)$ diikuti

ketidakteraturan menstruasi $(31,2 \%)$, serta perpanjangan durasi menstruasi (5,3\%). Berdasarkan studi epidemiologi pada populasi remaja (berusia 12-17 tahun) di Amerika Serikat, Klein dan Litt melaporkan prevalensi dismenorea mencapai 59,7\%. Studi ini juga melaporkan bahwa dismenorea menyebabkan $14 \%$ remaja sering tidak masuk sekolah (Bonde, Lontong, \& Moningka, 2014). Di Indonesia angka kejadian dismenorea terdiri dari $54,89 \%$ dismenorea primer dan $9,36 \%$ dismenorea sekunder (Sari, 2013). Menurut Dewi (2012), disminore adalah nyeri sewaktu haid yaitu terdiri dari gejala yang kompleks berupa kram perut bagian bawah yang menjalar ke punggung atau kaki dan biasanya disertai gejala gastrointestinal dan gejala neurologis seperti kelemahan umum. Sari (2013) dalam Savitri (2015) mengatakan keluhan nyeri haid dapat terjadi bervariasi mulai dari yang ringan sampai berat.Keparahandismenorea berhubungan langsung dengan lama dan jumlah darah haid. Biasanya nyeri muncul sebelum keluarnya haid dan meningkat pada hari pertama dan kedua. Biasanya gejala dismenorea primer terjadi pada wanita usia produktif 3-5 tahun setelah mengalami haid pertama dan wanita yang belum pernah hamil. 
Sebagian wanita

mendapatkan menstruasi tanpa

keluhan, namun tidak sedikit dari

mereka yang mendapatkan

menstruasi disertai keluhan

sehingga mengakibatkan rasa

ketidaknyamanan berupa

dismenore. Selanjutnya proses

menstruasi ini berlangsung secara

rutin setiap bulan pada setiap

perempuan normal yang dimulai

sekitar 14 hari setelah ovulasi.

Namun banyak diantaranya dalam

periode menstruasi ini mengalami

masalah, khususnya pada masa

remaja sering mengalami nyeri haid

(Dismenorea) (Sukarni \& Wahyu, 2013).

Diantara keluhan tersebut, kejang-kejang menstruasi dari beberapa derajat mempengaruhi lebih banyak dari suatu perkiraan $50 \%$ akan menggambarkan kejangkejang menstruasi sebagai berat. Survei-survei dari gadis-gadis remaja menujukkan bahwa lebih dari $90 \%$ dari gadis-gadis melaporkan mempunyai kejangkejang menstruasi (Sukarni \& Margareth, 2013).

Menarche adalah haid yang pertama kali. Menstruasi merupakan perdarahan yag teratur dari uterus sebagai tanda bahwa organ kandungan telah berfungsi matang. Umumnya remaja yang mengalami menarche adaah pada usia 12-16 tahun. Periode ini akan mengubah perilaku dari berbagai aspek, misalnya osikologi dan lainnya. Pada wanita siklus menstruasi normal terjadi setiap 22 -35 hari, dengan lamanya menstruasi 207 hari (Kusmiran, 2011).

Status gizi mempunyai peran penting dalam kesehatan reproduksi. Gizi kurang atau terbatas selain akan menyebabkan terpengaruhnya pertumbuhan, fungsi organ tubuh, juga akan menyebabkan terganggunya fungsi reproduksi. Hal ini berdampak pada gangguan haid, tetapi akan membaik jika asupannutrisinya baik. Asupan energy bervariasi sepanjang siklus haid, terjadi peningkatan asupan energy pada fase luteal dibandingkan dengan fase folekuler. Sehingga estrogen mengakibatkan efek penekann atau penurunan terhadap nafsu makan (Marmi, 2013).

Menurut penelitian Handayani \& Rahayu (2014), mengatakan bahwa faktor-faktor yang menyebabkan disminore adalah Usia menarche, olah raga tidak teratur, riwayat keluarga, dan usia menarce lebih awal. Penelitian yang dilakukan Alatas \& Larasati (2016) ditemukan bahwa bentuk disminore primer yang banyak dialami oleh remaja adalah kekauan atau kejang dibagian bawah perut.Rasanya sangat tidak nyaman sehingga menyebabkan mudah marah, gampang tersinggung, mual, muntah, kenaikan berat badan, perut gembung, punggung terasa nyeri, sakit kepala, tegang, lesu dan depresi.

Berdasarkan studi

pendahulan yang dilakukan peneliti yang dilakukan di SMPN 57

Kecamatan Pinang Raya Bengkulu Utara pada tahun 2018 jumlah data siswwi yaitu sebanyak 47 orang. Dari survey awal yang dilakukanpada tanggal 25 Februari 2018 dilakukan wawancara pada 5 orang siswi SMP di SMPN 57 Kecamatan Pinang Raya didapatkan 1 orang tidak 
mengalami disminore dengan status gizi baik (normal) dan umur menarche 12 tahun sedangkan 4 orang mengalami dismonore dengan pembagian 3 orang padastatsu gizi baik (normal) denga usia menarche 12 tahun dan 1 orang dengan status gizi kurus (kurang BB tingkat ringan) dengan umur menarche 12 tahun.

Pengukuran status gizi dengan menggunakan BMT. Rumusan masalah dalam penelitian ini adalah "Apakah terdapat hubungan usia menarche dan status gizi dengan kejadian disminore pada siswi SMP Kelas 2 di SMPN 57 Kecmatan Pinang Raya Kabupaten Bengkulu Utara?". Tujuan dilakukannya penelitian ini adalah untuk mempelajari hubungan antara usia menarche dan status gizi dengan kejadian disminore pada siswi SMP kelas 2 di SMPN 57 Kecamatan Pinang Raya Kabupaten Bengkulu Utara.

B. Metode Penelitian

Penelitian ini menggunakan metode Survey Analitik dengan pendekatan Cross Sectional.
Populasi dalam penelitian ini adalah seluruh siswi kelas 1 yang sudah mengalami menstruasi di SMPN 57 Kecamatan Pinang Raya Kabupaten Bengkulu Utara pada tahun 2017 berjumlah 43 orang. Teknik Pengambilan sampel dalam penelitian ini dilakukan dengan teknik Total Sampling. Teknik Pengumpulan menggunakan Data Primer dan Data Sekuder. Teknik Analisis Data menggunakan $\mathrm{Uji}$ Normalitas Data, Analisis Univariat dan Analisis Bivariat. Analisis bivariat merupakan hasil dari variabel yang diduga mempunyai hubungan dengan variabel terikat. Analisa yang digunakan adalah tabulasi silang.Untuk menguji hipotesis dilakukan analisa statistik dengan menggunakan Kendall Tau ( $\tau)$.

C. Hasil Penelitian

1. Analisis Univariat Analisis univariat bertujuan untuk mengetahui distribusi frekuensi variabel bebas (usia menarche dan status gizi) dan variabel terikat (kejadian Disminore).

Tabel 1

Distribusi Frekuensi Usia Menarche di SMPN 57 Kecamatan Pinang Raya Kabupaten Bengkulu Utara

\begin{tabular}{cccc}
\hline No & Usia Menarche & Frekuensi & $\begin{array}{r}\text { Persentase } \\
(\%)\end{array}$ \\
\hline 1 & $<12$ tahun & 14 & 37,8 \\
2 & $12-14$ tahun & 23 & 62,2 \\
\hline 3 & $>14$ tahun & 0 & 0,0 \\
\hline & Jumlah & 37 & 100,0 \\
\hline
\end{tabular}

Berdasarkan Tabel 1 dapat diketahui bahwa dari 37 responden, 14 orang $(37,8 \%)$ usia menarche
$<12$ tahun, 23 orang $(62,2 \%)$ usia menarche $12-14$ tahun, $(0 \%)$ usia menarche $>14$ tahun. 
Tabel 2

Distribusi Frekuensi Status Gizi di SMPN 57 Kecamatan Pinang Raya Kabupaten Bengkulu Utara

\begin{tabular}{clcc}
\hline N & \multicolumn{1}{c}{ Status Gizi } & Frekuensi & $\begin{array}{c}\text { Persentase } \\
(\%)\end{array}$ \\
\hline 1 & Kurus & 23 & 62,2 \\
2 & Normal & 8 & 21,6 \\
3 & Gemuk & 5 & 13,5 \\
4 & Obesitas & 1 & 2,7 \\
\hline \multicolumn{2}{r}{ Jumlah } & 37 & 100,0 \\
\hline
\end{tabular}

Berdasarkan Tabel 2

diketahui bahwa dari 37 responden, 23 orang $(62,2 \%)$ dengan status gizi kurus, 8 orang $(21,6 \%)$ dengan status gizi normal, 5 orang $(13,5 \%)$ dengan status gizi gemuk dan 1 orang $(2,7 \%)$ dengan status gizi obesitas.

Tabel 3

Distribusi Frekuensi Disminore di SMPN 57 Kecamatan Pinang Raya Kabupaten Bengkulu Utara

\begin{tabular}{cccc}
\hline No & Disimore & Frekuensi & $\begin{array}{c}\text { Persentase } \\
(\%)\end{array}$ \\
\hline 1 & Tidak Nyeri & 11 & 29,7 \\
2 & Nyeri Ringan & 16 & 43,2 \\
3 & Nyeri Sedang & 10 & 27,0 \\
\hline & Jumlah & 37 & 100,0 \\
\hline
\end{tabular}

Berdasarkan Tabel 3 dapat diketahui bahwa dari 37 responden terdapat 11 orang $(29,7 \%)$ dengan tidak nyeri, 16 orang $(43,2 \%)$ dengan nyeri ringan, dan 10 orang (27\%) pada nyeri sedang.

\section{Analisis Bivariat}

Analisis univariat bertujuan untuk mengetahui distribusi frekuensi variabel bebas (usia menarche dan status gizi) dan variabel terikat (kejadian Disminore).

Tabel 4

Hubungan Usia Menarche dengan Kejadian Disminore SMPN 57 Kecamatan Pinang Raya Kabupaten Bengkulu Utara

\begin{tabular}{ccccc}
\hline Usia & Disminore & Total & $\tau$ & Approx.sig \\
\hline
\end{tabular}




\begin{tabular}{lccccccc}
\hline \multirow{2}{*}{ Menarche } & Tidak & Nyeri & Nyeri & & & & \\
& Nyeri & Ringan & Sedang & & & \\
\hline$<12$ Tahun & 2 & 8 & 4 & 14 & & \\
12-14 & 9 & 8 & 6 & 23 & $-0,169$ & 0,251 \\
Tahun & 9 & & & & & & \\
\hline \multicolumn{1}{c}{ Jumlah } & 11 & 16 & 10 & 37 & & \\
\hline
\end{tabular}

Berdasarkan tabel. tabulasi silang antara usia menarche dengan Disminore di SMPN 57 Kecamatan Pinang Raya Kabupaten Bengkulu Utara, dapat diketahui bahwa dari 14 orang usia $<12$ tahun, terdapat 2 orang tidak nyeri, 8 orang nyeri ringan, 4 orang nyeri sedang. Dari 23 orang usia 12-14 tahun terdapat 9 orang tidak nyeri 8 orang nyeri ringan dan 6 orang nyeri sedang. Pada usia $>14$ tahun tidak ada responden yang menarche pada umur tersebut.

Hasil uji statistik Kendalls tau didapat nilai $\tau=-0,169$ dengan approx.sig. $=0,251>0,05$ berarti tidak signifikan, maka Ho diterima dan Ha ditolak. Jadi Tidak ada hubungan usia menarche dengan kejadian dismonire pada siswi di SMPN 57 Kecamatan Pinang Raya Kabupaten Bengkulu Utara.

Tabel 5

Hubungan Status Gizi dengan Kejadian Disminore SMPN 57 Kecamatan Pinang Raya Kabupaten Bengkulu Utara

\begin{tabular}{|c|c|c|c|c|c|c|}
\hline \multirow[b]{2}{*}{ Status Gizi } & \multicolumn{3}{|c|}{ Disminore } & \multirow[b]{2}{*}{ Total } & \multirow[b]{2}{*}{$\tau$} & \multirow[b]{2}{*}{ Approx.sig } \\
\hline & $\begin{array}{l}\text { Tidak } \\
\text { Nyeri }\end{array}$ & $\begin{array}{l}\text { Nyeri } \\
\text { Ringan }\end{array}$ & $\begin{array}{l}\text { Nyeri } \\
\text { Sedang }\end{array}$ & & & \\
\hline Kurus & 2 & 12 & 9 & 23 & \multirow{4}{*}{$-0,512$} & \multirow{4}{*}{0,000} \\
\hline Normal & 5 & 2 & 1 & 8 & & \\
\hline Gemuk & 3 & 2 & 0 & 5 & & \\
\hline Obesitas & 1 & 0 & 0 & 1 & & \\
\hline Jumlah & 11 & 16 & 10 & 37 & & \\
\hline
\end{tabular}

Dari tabulasi silang status gizi dengan disminore di atas dapat diketahui dari 23 orang status gizi kurus, terdapat 2 orang tidak nyeri 12 orang nyeri ringan dan 9 orang nyeri sedang. Dari 8 orang status gizi normal, terdapat 5 orang tidak nyeri 2 orang nyeri ringan dan 1 orang nyeri sedang. Dari 5 orang status gizi gemuk, terdapat 3 orang 
tidak nyeri 2 orang nyeri ringan, dari 1 orang obesitas dia tidak nyeri. Uji statistik yang digunakan adalah uji statistic Kendall Tau ( $\tau$ ).

Hasil uji Kendalls tau didapat nilai $\tau=-0,512$ dengan appox.sig. $=$ $0,000<0,05$ berarti signifikan, maka
Ho ditolak dan Ha diterima. Jadi Ada hubungan status gizi dengan kejadian disminore pada wanita usia subur di Desa Bumi Harjo Kecamatan Pinang Raya Kabupaten Bengkulu Utara.

Tabel 6

Hubungan Kategori Usia Menarche dan Status Gizi dengan Kejadian Disminore SMPN 57 Kecamatan Pinang Raya Kabupaten Bengkulu Utara

\begin{tabular}{|c|c|c|c|c|c|c|c|}
\hline \multirow{2}{*}{$\begin{array}{c}\text { Usia } \\
\text { Menarch } \\
\text { e }\end{array}$} & \multirow[b]{2}{*}{$\begin{array}{c}\text { Status } \\
\text { Gizi }\end{array}$} & \multicolumn{3}{|c|}{ Disminore } & \multirow[b]{2}{*}{ Total } & \multirow[b]{2}{*}{$\tau$} & \multirow[b]{2}{*}{ Approx.sig } \\
\hline & & $\begin{array}{l}\text { Tidak } \\
\text { Nyeri }\end{array}$ & $\begin{array}{c}\text { Nyeri } \\
\text { Ringan }\end{array}$ & $\begin{array}{c}\text { Nyeri } \\
\text { Sedang }\end{array}$ & & & \\
\hline \multirow{2}{*}{$\begin{array}{c}<12 \\
\text { Tahun }\end{array}$} & Kurus & 1 & 7 & 4 & 12 & \multirow{3}{*}{$-0,382$} & \multirow{3}{*}{0,157} \\
\hline & Normal & 1 & 1 & 0 & 2 & & \\
\hline \multicolumn{2}{|c|}{ Total } & 2 & 8 & 4 & 14 & & \\
\hline \multirow{4}{*}{$\begin{array}{l}12-14 \\
\text { Tahun }\end{array}$} & Kurus & 1 & 5 & 5 & 11 & \multirow{5}{*}{$-0,519$} & \multirow{5}{*}{0,000} \\
\hline & $\underset{\mid}{\text { Norma }}$ & 4 & 1 & 1 & 6 & & \\
\hline & Gemuk & 3 & 2 & 0 & 5 & & \\
\hline & $\begin{array}{c}\text { obesit } \\
\text { as }\end{array}$ & 1 & 0 & 0 & 1 & & \\
\hline Jun & & 9 & 8 & 6 & 23 & & \\
\hline
\end{tabular}

a. Kategori usia $<12$ tahun

Dari 12 orang status gizi kurus terdapat 1 orang tidak nyeri 7 orang nyeri ringan 4 orang nyeri sedang, dari 2 orang gizi normal terdapat 1 orang tidak nyeri dan 1 orang nyeri ringan.

Hasil uji Kendalls tau didapat nilai $\tau=-0,382$ dengan approx.sig. $=0,157>0,05$ berarti tidak signifikan, maka Ho diterima dan Ha ditolak. Jadi Tidak ada hubungan usia menarche dengan kejadian dismonire Pada siswi SMP kelas 1 di SMPN 57 Kecamatan Pinang Raya Bengkulu Utara.

b. Kategori usia 12-14 tahun
Dari 11 orang gizi kurus terdapat 1 orang tidak nyeri 5 orang nyeri ringan 5 orang nyeri sedang.Dari 6 orang gizi normal terdapat 4 orang tidak nyeri 1 orang nyeri ringan 1 orang nyeri sedang. Dari 5 orang status gizi gemuk terdapat 3 orang tidak nyeri 2 orang nyeri ringan, dan 1 orang obesitas tidak nyeri.

Hasil uji Kendalls tau didapat nilai $\tau=-0,519$ dengan appox.sig. = $0,000<0,05$ berarti signifikan, maka Ho ditolak dan Ha diterima. Jadi Ada hubungan status gizi dengan kejadian disminore Pada siswi SMP kelas 1 di SMPN 57 Kecamatan Pinang Raya Bengkulu Utara. 


\section{Pembahasan}

Dari 23 orang usia 12-14 tahun terdapat 9 orang tidak nyeri, 8 orang nyeri ringan dan 6 orang nyeri sedang. Usia tersebut termasuk usia ideal dalam menarche, sesuai dalam teori Kusmiran (2011). Responden yang sesuai dengan usiaidela menarche tetapi masih mengalami disminore, hal itu dikarenakan mereka jarang melakukan olah raga dan aktifitas fisik.Kegiatan yang dilakukan adalah sekolah dan belajar, sehingga jarang melakukan olahraga ataupun mengikuti kegiatan ekstrakulikuler di sekolah. Hasil analisis hubungan antara usia menarche dengan kejadian disminore diperoleh responden yang mengalami disminore pada usia < 12 sebanyak 12 orang, sedangkan responden yang menarche pada usia 12-14 tahun yang mengalami disminore sebanyak 14 orang. Didapatkan hasil uji statistik Kendalls tau didapat nilai $\tau=-0,169$ dengan approx.sig. $=0,251>0,05$ berarti tidak signifikan, maka Ho diterima dan Ha ditolak. Jadi Tidak ada hubungan usia menarche dengan kejadian dismonire pada siswi di SMPN 57 Kecamatan Pinang Raya Kabupaten Bengkulu Utara.

Berdasarkan penelitan yang dilakukan oleh Wahyuni (2014) dari uji statistic yang dilakukan diperoleh nilai $p=0,381$ maka dapat disimpulkan tidak ada perbedaan proporsi kejadian disminore antara responden yang menarche pada usia $<12$ tahun, 12-14 tahun (tidak ada hubungan yang signifikan antara usia menarche dengan kejadian disminore)
Dari 23 orang status gizi kurus terdapat 2 orang tidak nyeri (Nn. M dan Nn. S) hal tersebut disebabkan karena tingginya akivitas (kegiatan estrakulikuler) sehingga otot rahim menjadi lebih rileks dan tidak megalami nyeri saat menstruasi. Hal tersebut sama dengan penelitian yang telah dilakukan oleh Purba, Sarumpaet, \& Jemadi (2013) yang mengatakan bahwa proporsi disminore primer tertinggi pada responden yang tidak pernah berolahraga yaitu $85,80 \%$ dan terendah pada respoden yang sering berolahraga yaitu $70,60 \%$ dengan nilai $p=0,0019$ yang artinya terdapat hubungan antara olahraga dengan kejadian disminore primer.

Pada 12 orang dengan status gizi kurus yang mengalami nyeri ringan dan 9 orang nyeri sedang. Status gizi yang kurus selain akan mempengaruhi pertumbuhan, fungsi organ tubuh, juga akan menyebabkan terganggunya haid, tetapi akan membaik jika asupan nutrisinya baik. Pada remaja wanita perlu mempertahankan status gizi yang baik dengan cara mengkonsumsi makanan seimbang makanan seimbang karena sangat diperlukan saat menstruasi.

Gizi yang kurang atau terbatas selain akan memengaruhi pertumbuhan, fungsi organ tubuh, juga akan menyebabkan terganggunya fungsi reproduksi. Hal ini akan berdampak pada gangguan haid, tetapi akan membaik jika asupan nutrisinya baik. Pada remaja wanita perlu mempertahankan status gizi yang baik, dengan cara mengkonsumsi makanan seimbang karena sangat dibutuhkan pada saat haid, terbukti 
padaa saat haid tersebut terutma pada fase luteal akan terjadi peningkatan kebutuhan nutrisi (Sibagariang, 2010).

Pada 5 orang status gizi gemuk terdapat 3 orang tidak nyeri (Nn. F, Nn. S, dan Nn. M), 2 orang nyeri ringan ( $\mathrm{Nn}$. R dan Nn. A), dan dari 1 orang obesitas tidak nyeri saat menstruasi (Nn. D). Pada status gizi lebih (gemuk dan obesitas) dapat mengakibatkan disminore karena jaringan lemak yang berlebihan. Hal itulah yang menyebabkan terjadinya hiperplasi atau terdesaknya pembuluh darah karena jaringan lemak pada organ reproduksi wanita. Sehingga darah yang seharusnya mengalir pada masa menstruasi terganggu dan menyebabkan rasaa nyeri. Pada responden dengan status gizi gemuk tetapi tidak mengalami disminore dikarenakan mereka aktif dalam olahraga. Remaja yang jarang melakukan olahraga memiliki resiko 1,2 kali lebih besar mengalami disminore (Purba, Sarumpaet, \& Jemadi, 2013).

Dari hasil penelitian yang dilakukan, didapatkan hasil uji Kendalls tau didapat nilai $\tau=-0,512$ dengan appox.sig. $=0,000<0,05$ berarti signifikan, maka Ho ditolak dan Ha diterima. Jadi Ada hubungan status gizi dengan kejadian disminore pada siswi smp kelas 1 di smpn 57 kecamatan pinang raya kabupaten bengkulu utara.

Berdasarkan hasil analisis statistik yang menggunakan uji $C h i$ Square Test diperoleh nilai $\mathrm{p}=$ 0.008 , yang artinya terdapat hubungan yang bermakna antara status gizi dengan disminore primer (Beddu, Mukarramah, \& Lestahulu,
2015). Hasil penelitian ini sesuai dengan teori yang mengatakan bahwa status gizi merupakan permasalahan yang dapat menimbulkan disminore primer.

Dari 12 orang status gizi kurus terdapat 1 orang tidak nyeri (Nn. S). Responden mengatakan jika sering melakukan olahraga yaitu dengan rutin latihan bola voli di lapangan lingkungan rumahnya setiap sore bersama teman di sekitar rumahnya. Karena sering melakukan olahraga tersebut otototot perutnya menjadi rileks dan tidak tegang, sehingga saat menstruasi tidak mengalami neyri. Hal tersebut sama dengan penelitian yang telah dilakukan oleh Purba, Sarumpaet, \& Jemadi (2013) yang mengatakan bahwa proporsi disminore primer tertinggi pada responden yang tidak pernah berolahraga yaitu $85,80 \%$ dan terendah pada respoden yang sering berolahraga yaitu $70,60 \%$ dengan nilai $p=0,0019$ yang artinya terdapat hubungan antara olahraga dengan kejadian disminore primer.

Pada 7 orang nyeri ringan dengan status gizi kurus, dan 4 orang nyeri sedang yaitu $\mathrm{Nn}$. A, Nn. B, Nn. M dan Nn. A. Pada respon dengan usia menarche $<12$ tahun lebih beresiko mengalami disminore karena pada usia tersebut lebih mudah terkena endometritis, sehingga hal tersebut menyebabkan nyeri saat menstruasi. Status gizi yang kurang atau terbatas selain akan mempengaruhi pertumbuhan, fungsi organ tubuh, juga akan menyebabkan terganggunya fungsi reproduksi.

Hal itu pun sama dengan penelitian yang dilakukan oleh 
Purba Sarumpaet, \& Jemadi (2013) yang menyatakan bahwa proporsi disminore primer tertinggi pada umur menarche $<12$ tahun yaitu $83,70 \%$ dan terendah pada umur $>14$ tahun yaitu $46,20 \%$. Hasil uji statistic yang membandingkan umur menarche $<12$ tahun dnean umur 13-14 tahun (yang merupakan umur ideal remaja perempuan mengalami disminore primer). Hasil uji statistic dengan menggunakan uji chi square diperoleh nila $p=0,037$ yangbearti terdapat hubungan antara umur dengan kejadian disminore primer.

Pada 2 orang gizi normal terdapat 1 orang tidak nyeri (Nn. V), pada remaja putri perlu mempertahankan status gizi yang baik, dengan cara mengkonsumsi makanan seimbang karena sangat dibutuhkan pada saat haid. Pada fase luteal akan terjadi peningkatan kebutuhan nutrisi, dan bila diabaikan maka dampaknya akan terjadi keluhan-keluhan yang menimbulkan rasa nyeri.

Ada 1 orang nyeri ringan dengan status gizi normal.Pada responden $\mathrm{Nn}$. T dengan status gizi normal tetapi mengalami nyeri saat menstruasi, responden mengatakan jika dirinya jarang melakukan olahraga dan juga tidak mengikuti kegiatan ekstrakulikuler di sekolah. Nn.T mengatakan jika dia merasa sakit pada perut bagian bawahnya saat menstruasi dan sakit tersebut dirasakan pada sehari sebelum menstruasi dan 2-3 hari setelah menstruasi.

Hal tersebut sesuai dengan penelitian yang dilakukan oleh Wahyuni (2014) dari hasil uji statistik diperoleh nilai $p=0,028$ maka dapat disimpulkan ada perbedaan proporsi kejadian yang mengalami disminore antara responden yang olahraga secara teratur dengan yang olahraga tidak teratur (ada hubungan antara oahraga teratur dengan kejadian disminore).

Hasil uji Kendalls tau didapatkan 12 orang yang mengalami disminore dari 14 responden yang mengalami menarche pada umur $<12$ tahun didapat nilai $\tau=-0,382$ dengan approx.sig. $=0,157>0,05$ berarti tidak signifikan, maka Ho diterima dan Ha ditolak. Jadi tidak ada hubungan usia menarche dengan kejadian dismonire pada siswi SMP kelas 1 di SMPN 57 Kecamatan Pinang Raya Bengkulu Utara Hal tersebut sejalan dengan penelitian yang dilakukan oleh Suwarnisih, Agustin, \&. Cahyaningtyas (2017) menggunakan uji chi square terlihat Asimp.Sig sebesar 0,796. Karena Asimp.sig 0,288 $>0,05$. Maka dapat disimpulkaan bahwa tidak ada hubungan yang signifikn antara usia menarche dengan kejadian disminore. Hasil penelitian ini didukung dengan penelitian yang dilakukan Putrie (2014) yang menunjukkan bahwa tida ada hubungan usia menarche dengan disminore $(p=0,363)$.

Dari 11 orang gizi kurus terdapat 1 orang tidak nyeri (Nn. S), hal ini dikarenakan Nn. S aktif dalam kegiatan ekstrakulikuler di sekolahnya. Latihan-latihan olahraga yang ringan sangat dianjurkan untuk mngurangi disminore. Olahraga/senam merupakan salah satu teknik relaksasi yang dapat digunakan untuk mengurangi nyeri saat 
menstruasi. Hal ini disebabkan saat melakukan olahraga/senam tubuh akan menghasilkan endorphin. Endorphin dihasilkan di otak dan sumsum saraf tulang belakang. Sesuai dengan teori endhorfinenkafalin mengenai pemahaman mekanisme nyeri adalah ditemukannya reseptor opiate di membrane sinaps.

Pada status gizi kurus terdapat 5 orang nyeri ringan 5 orang nyeri sedang.Pada seseorang dengan statu gizi kurang lebih beresiko mengalami dsminore saat menstruasi karena kebutuhn nutrisinya yang tidak terpenuhi. Menurut penelitian yang dilakukan oleh Purba, Sarumpaet, \& Jemadi (2013) mengatakan bahwa jika dibandingkan status gizi rendah dengan status gizi normal, hasil uji statistic dengan menggunakan uji chi square diperoleh nilai $p=0,006$ yang bearti terdapat hubungan yang bermakna antar status gizi dengan kejadian disminore.

Dari 6 orang gizi normal terdapat 4 orang tidak nyeri 1 orang nyeri ringan 1 orang nyeri sedang. Dari 5 orang status gizi gemuk terdapat 3 orang tidak nyeri, 2 orang nyeri ringan, dan 1 orang obesitas tidak nyeri.

Hasil analisis terdapat 10 orang dengan status gizi kurus yang mengalami disminore, 2 orang dengan status gizi normal, dan 2 orang dengan statu gizi gemuk, maka didapatkan uji Kendalls tau didapat nilai $\tau=-0,519$ den ganappox.sig. $=0,000<0,05$ berarti signifikan, maka Ho ditolak dan $\mathrm{Ha}$ diterima. Jadi Ada hubungan status gizi dengan kejadian disminore Pada siswi SMP kelas 1 di SMPN
57 Kecamatan Pinang Raya Bengkulu Utara.

E. Kesimpulan

1. Dari 37 responden terdapat 23 orang $(62,2 \%)$ dengan usia menarche 12-14 tahun.

2. Dari 37 responden terdapat 23 orang $(62,2 \%)$ dengan status gizi kurus.

3. Dari 37 responden terdapat 16 orang $(43,2 \%)$ nyeri ringan saat menstruasi.

4. Tidak ada hubungan usia menarche dengan kejadian dismonire pada Siswi SMPN Kelas 2 di SMPN 57 Kecamatan Pinang Raya Kabupaten Bengkulu Utara

5. Ada hubungan status gizi dengan kejadian disminore pada Siswi SMPN Kelas 2 di SMPN 57 Kecamatan Pinang Raya Kabupaten Bengkulu Utara

Daftar Pustaka

Beddu, S., Mukarramah, S., \& Lestahulu, V. (2015). Hubungan Status Gizi dan Usia Menarche dengan Disminore Primer pada Remaja Putri. The Southeast Asian Journal of Midwifery, 1 (1), 16-21. Diunduh dari : journal-aipkind.or.id? index.php > seajom > article > download.

Bonde, F. M. P, Lintong, F., \& Moningka, M. (2014). Pengaruh Kompres Panas terhadap Penurunan Derajat Nyeri Haid pada Siswi SMA dan SMK Yadika Kopandakan II. Jurnal eBiomedik, 2 (1). Diunduh dari : 
https://ejournal.unsrat.ac.id/ index.php/ebiomedik/article/ view/3751/3274.

Dewi, N. S. (2012). Biologi Reproduksi. Yogyakarta : Rihana Medika.

Handayani, E. Y. \& Rahayu, L. S. (2014). Faktor-Faktor yang Berhubungan dengan Nyeri Haid Menstruasi (Disminore) pada Remaja Putri di Beberapa SMA di Kabupaten Rokan Hulu. Jurnal Maternity and Neonatal, 1 (4), 161-171. Diunduh dari : http://ejournal.upp.ac.id/ind ex.php/akbd/article/view/11 07.

Kusmiran, E. (2011). Kesehatan Reproduksi Remaja dan Wanita. Jakarta: Salemba Medika

Larasati, T. A. \& Alatas, F. (2016). Disminore Primer dan Faktor Resiko Disminore Primer pada Remaja. Majority, 5 (3), 79-84. Diunduh dari : juke.kedokteran.unila.ac.id, index.php > majority > article , download.

Marmi. (2013). Kesehatan Reproduksi. Jakarta : Pustaka Pelajar.

Purba, F. S., Sarumpaet, S. M., \& Jemadi. (2013). Faktorfaktor yang Berhubungan dengan Disminore pada Siswi SMK N 10 Medan Tahun 2013. Jurnal Gizi, Kesehatan Reproduksi dan Epidemiologi, 2 (5). Diunduh dari :

https://jurnal.usu.ac.id/index. php/gkre/article/view/4060/ 1894.

Putrie, H. C. (2014). Hubungan antara Tingkat Pengetahuan,
Usia, Menarche, Lama

Menstruasi, Lama

Menstruasi, dan Riwayat

Keluarga dengan Kejadian

Dismenore pada Siswi di

SMPN 2 Kartasura

Kabupaten Sukoharjo.

Skripsi. Fakultas IImu

Kesehatan Universitas

Muhammadiyah Surakarta.

Sari, W. P. (2013). Efektifitas Terapi

Farmakologis dan Non

Farmakologis terhadap Nyeri

Haid (Dismonire) pada Siswi

XI SMA 1 di SMA Negeri 1

Pemangkat. Skripsi. Fakultas

Kedokteran Universitas

Tanjungpura.

Savitri, R. (2015). Gambaran Skala Nyeri Haid pada Usia Remaja. Jurnal Keperawatan Aisyah, 2 (2), 25-29. Diunduh dari : http://jurnalkeperawatan.stik es-

aisyiyahbandung.ac.id/file/R ahayuSavitri_JKA_Vol2_No2. Desember_2015_04.pdf

Sibagariang, E. E. (2010). Gizi Dalam Kesehatan Reproduksi. Jakarta: Penerbit Buku Kesehatan

Sukarni, I \& Margareth. (2013). Kehamilan, Persalinan dan Nifas. Yogyakarta : Nuha Medika.

Sukarni, I. \& Wahyu. (2013). Buku Ajar Keperawatan Maternitas. Yogyakarta : Nuha Medika

Suwarnisih, Agustin, K., \&.

Cahyaningtyas, A. Y. (2017).

Hubungan Usia Menarche dengan Kejadian Disminore pada Remaja Putri di SMPN 17 Surakarta. Jurnal Maternal, 2 (1), 46-54. Diunduh dari : https://ejurnal.stikesmhk.ac. 
id/index.php/jurnal_ilmiah_m aternal/article/viewFile/576/ 515.

Wahyuni, R. (2014). Faktor-Faktor yang Berhubungan dengan Nyeri Haid Menstrasi (Disminore) pada Remaja Putri di Beberapa SMA di Kabupaten Rokan Hulu Tahun 2013. Jurnal
Maternity and Neonatal, 1 (1), 183-195. Diunduh dari :

e-journal.upp.ac.id s index.php > akbd > article , download.

1. 